Revista Vol. 24(48)

Prolegómenos julio-diciembre - ISSN: 0121-182x · e-ISSN: 1909-7727

\title{
La conciliación contenciosa administrativa. Análisis desde la tutela judicial efectiva*
}

\author{
Edilsa del Socorro Torres Osorio ${ }^{a}$
}

\begin{abstract}
Resumen: la conciliación contenciosa administrativa es un procedimiento complejo, el cual, conforme a las estadísticas, no muestra resultados óptimos en lo que respecta a producir menores demandas y condenas al Estado. Es por esto que el propósito de esta investigación es verificar si la conciliación contenciosa administrativa cumple con los requisitos de la tutela judicial efectiva (TJE). Usamos esta última por analogía para llegar a nuestro objetivo así: 1. El derecho de acceso a la jurisdicción, 2. El derecho a obtener un procedimiento de conciliación fundado en el derecho objetivo, 3. El derecho a los recursos que las leyes establezcan contra las resoluciones judiciales, 4. El derecho a la ejecución de las actas de conciliación, 5. El derecho a la inmodificabilidad de los acuerdos logrados y 6 . El derecho a no sufrir indefensión en el proceso de conciliación. Como resultado, se obtiene que se vulneran dos de las garantías enunciadas, la primera es que el artículo 243 numeral 4 del Código de Procedimiento Administrativo y de lo Contencioso Administrativo no permite apelar a las partes en conflicto, el auto que aprueba o deniega la homologación del acuerdo, y la segunda es que, por el procedimieno tan complejo, se obtienen menos del $30 \%$ de homologaciones a los acuerdos, lo que hace del mecanismo de resolución de conflictos uno poco eficaz.
\end{abstract}

Palabras clave: administración de justicia; conciliación; contenciosa administrativa; tutela judicial efectiva

Recibido: 28 de noviembre de 2020 Aceptado: 27 de octubre de 2021

Disponible en línea: 27 de diciembre de 2021

Cómo citar: Torres Osorio, E. del S. (2021). La conciliación contenciosa administrativa. Análisis desde la tutela judicial efectiva. Prolegómenos, 24(48), 93-108. https://doi.org/10.18359/prole.5457

* Artículo de investigación. Universidad de Investigación y Desarrollo

a Doctora en derecho, Universidad de Salamanca. Docente-investigadora, Universidad de Investigación y Desarrollo Bucaramanga, Santander.

Correo electrónico: etorres3@udi.edu.co 


\title{
Administrative Dispute Settlement. Analysis from the Due Process of Law
}

\begin{abstract}
: administrative dispute settlement is a complex procedure, which, according to statistics, does not show optimal results in producing fewer lawsuits and sentences against the State. Thus, this research aims to verify whether administrative dispute settlement follows the due process of law (DPL). We use the latter as an analogy to reach our goal: 1) the right of access to jurisdiction, 2) the right to obtain a settlement procedure based on objective law, 3) the right to remedies established by law against judicial decisions, 4) the right to execute settlement agreement certificates, 5) the right to the unchangeability of the agreements reached, and 6) the right not to be defenseless in the settlement process. We found that two of the listed guarantees are violated. The first is that Article 243 (4) of the Code of Administrative Procedure and Administrative Litigation does not allow the parties in conflict to appeal the order that approves or denies the agreement ratification. The second is that less than $30 \%$ of the agreements are ratified due to the complexity of the procedure, rendering the conflict resolution mechanism ineffective.
\end{abstract}

Keywords: administration of justice; settlement; administrative litigation; due process of law

\section{A conciliação contenciosa administrativa. Análise a partir da tutela judicial efetiva}

Resumo: a conciliação contenciosa administrativa é um procedimento complexo, o qual, conforme estatísticas, não mostra ótimos resultados no que diz respeito a produzir menores demandas e condenações ao Estado. Por isso, o objetivo desta pesquisa é verificar se a conciliação contenciosa administrativa cumpre com os requisitos da tutela judicial efetiva. Assim, usamos esta última por analogia para chegar ao nosso objetivo: 1) o direito de acesso à jurisdição; 2) o direito de obter um procedimento de conciliação fundado no direito objetivo; 3) o direito aos recursos que as leis estabeleçam contra as resoluções judiciais; 4) o direito à execução das atas de conciliação; 5) o direito à não modificação dos acordos estabelecidos e 6) o direito a não sofrer indefesa no processo de conciliação. Como resultado, obtém-se que são violadas duas garantias enunciadas: a primeira, que se encontra no artigo 243, numeral 4, do Código de Procedimento Administrativo e do Contencioso Administrativo, o qual não permite que as partes em conflito apelem, o auto que aprova ou denega a homologação do acordo; a segunda, pelo procedimento tão complexo, obtêm-se menos de 30 \% de homologações aos acordos, o que faz do mecanismo de resolução de conflito pouco eficaz.

Palavras-chave: administração de justiça; conciliação; contenciosa administrativa; tutela judicial efetiva 


\section{Introducción}

Este análisis de la tutela judicial efectiva (TJE) en la conciliación fue desarrollado por la autora en trabajos anteriores realizados con las leyes de mediación en España (Torres Osorio, 2013) y ahora en Colombia en las leyes de la conciliación extrajudicial en derecho privado (pendiente de publicación). Se clarifica que el tema aquí tratado no se ha abordado en los textos antes señalados y se trata desde la normatividad vigente a la fecha de presentación del artículo.

En esta investigación se verifica si el contenido de la TJE cumple en el desarrollo del procedimiento conciliatorio contencioso administrativo, siendo este el más complejo entre los existentes (conciliación civil, comercial, laboral y contencioso administrativo), por ser una entidad pública uno de los intervinientes y por estarse conciliando cuestiones del derecho público.

Esta investigación pretende demostrar que, debido a su complejidad, la conciliación contenciosa administrativa no cumple con todos los requisitos de la TJE. Es una herramienta para que el legislador o el Ministerio de Justicia y del Derecho, y la misma Procuraduría delegada en esta jurisdicción, busquen y presenten soluciones de mejora para este mecanismo de resolución de conflictos tan importante para el derecho público.

En la Constitución Política (CP) colombiana no encontramos el término de tutela judicial efectiva (TJE) expresamente consagrado, razón por la cual debemos acudir a la interpretación que hace la Corte Constitucional sobre esta institución jurídica, a través de su jurisprudencia.

Para analizar si la conciliación en Colombia es aplicada bajo el criterio de la TJE, debemos partir del concepto y del tratamiento de esta en la CP y en la jurisprudencia de la Corte Constitucional colombiana.

La Corte Constitucional en la sentencia T-550 de 2016, indica que

[...] [e]l fundamento del derecho a la tutela judicial efectiva se encuentra principalmente en los artículos 1, 2, 29 y 229 de la Constitución Política, así como también en los artículos 25 de la Convención
Americana Sobre Derechos Humanos y 14 del Pacto Internacional de Derechos Civiles y Políticos.

El artículo 229 de la CP expresa: "Se garantiza el derecho de toda persona para acceder a la administración de justicia. La ley indicará en qué casos podrá hacerlo sin la representación de abogado" y el artículo 29: "El debido proceso se aplicará a toda clase de actuaciones judiciales y administrativas".

En la sentencia T-550/16 encontramos que la Corte $^{1}$ señala que el contenido de la TJE es

[...] (i) el derecho de acción o de promoción de la actividad jurisdiccional, (ii) el derecho a que subsistan en el orden jurídico una gama amplia y suficiente de mecanismos judiciales para la efectiva resolución de los conflictos, (iii) contar con la posibilidad de obtener la prueba necesaria a la fundamentación de las peticiones que se eleven ante el juez, (iv) el derecho a una decisión de fondo a sus pretensiones, (v) el derecho a que existan procedimientos adecuados, idóneos y efectivos para la definición de las pretensiones y excepciones debatidas, y (vi) el derecho a que los procesos se desarrollen en un término razonable sin dilaciones injustificadas y con observancia de las garantías propias del debido proceso.

Por lo anterior, sintetizando, podemos decir que, tal como lo expresa el tratadista Garberí Llobregat (2008, p. 19), la tutela judicial efectiva contiene los siguientes derechos:

1. El derecho de acceso a la jurisdicción.

2. El derecho a obtener de los tribunales un procedimiento fundado en el derecho objetivo, que será de fondo cuando concurran todos los presupuestos procesales y que observará los requisitos de la motivación y la congruencia.

3. El derecho a los recursos que las leyes establezcan contra las resoluciones judiciales.

4. El derecho a la ejecución de las resoluciones judiciales.

1 En igual sentido, ver la sentencia C-426/02. 
5. El derecho a la inmodificabilidad de las resoluciones judiciales firmes fuera de los cauces legalmente establecidos al efecto.

6. El derecho a no sufrir indefensión en el proceso.

Así las cosas, en la investigación plasmada por el trabajo continuo de la autora se determinan por analogía los seis criterios de la TJE y se llevan a la reglamentación de la conciliación contenciosa administrativa. Se llega a la conclusión de que en esta conciliación se vulneran dos de sus componentes: el derecho a los recursos directamente, pues el artículo 243, numeral 4 del Código de Procedimiento Administrativo y de lo Contencioso Administrativo (CPACA) establece tal vulneración al no permitir que las partes puedan interponer recurso de apelación al auto que aprueba las conciliaciones extrajudiciales o judiciales, el cual solo podrá ser interpuesto por el Ministerio Público. También se encuentra vulnerada la TJE en la conciliación contenciosa administrativa en el tiempo que tarda obtener resultado de la misma, desde que se presenta la solicitud de conciliación hasta que se logre acuerdo y este sea homologado por la jurisdicción, afectando, por tanto, la ejecutabilidad de los acuerdos y la eficacia de los mecanismos alternativos de solución de conflictos.

\section{Metodología}

El enfoque que se utiliza en esta investigación es el cualitativo, ya que conlleva un análisis del desarrollo de la conciliación contenciosa administrativa desde una perspectiva holística y subjetiva.

El método de investigación es el sistemático jurídico, pues se han ordenado los conocimientos de la conciliación, agrupándolos coherentemente a los parámetros trazados en la TJE. Desde esta perspectiva del método sistemático jurídico se contempló la conciliación dentro de un todo, no de forma aislada al sistema jurídico. Debió ser abordada de forma integral para conocer y comprender el sentido y alcance de ella en la totalidad del ordenamiento jurídico.

La hipótesis que se pretende demostrar en este artículo es: la figura de la conciliación contenciosa administrativa es procesalmente adecuada y admisible en cuanto a respetar los principios constitucionales contenidos en la TJE. La investigación gira en torno a analizar y comparar por analogía los seis contenidos básicos sobre la TJE respecto a la conciliación contenciosa $\mathrm{o}$ administrativa.

\section{Discusión}

Como se indicó anteriormente, en la CP colombiana no se encuentra el término de tutela judicial efectiva (TJE) expresamente consagrado como sí ocurre, por ejemplo, en la Constitución Política de España, que establece en su artículo 24: "1. Todas las personas tienen derecho a obtener la tutela efectiva de los jueces y tribunales en el ejercicio de sus derechos e intereses legítimos, sin que, en ningún caso, pueda producirse indefensión [...]”. La normatividad colombiana expresa tácitamente la TJE estableciéndola como el derecho al debido proceso y es la jurisprudencia constitucional la que desarrolla y lo equipara con el contenido de la TJE. Tal es el caso de la sentencia T-550/2016, en esta, la Corte Constitucional expresa "el derecho a la administración de justicia, también denominado derecho a la tutela judicial efectiva".

En igual sentido, la sentencia T-608/19 reitera que el derecho de acceso a la administración de justicia también se denomina "derecho a la tutela judicial efectiva”. También establece las dimensiones que amparan el acceso efectivo a la administración de justicia y el desarrollo de las garantías de este derecho, que son las mismas expresadas anteriormente por Garberí Llobregat (2008). Ahora bien, en la sentencia C-159/16, la Corte conmina al legislador a que debe definir y crear los diferentes procesos judiciales desde el contenido completo de la TJE.

Por su parte, González Pérez (2001) manifiesta que la tutela judicial despliega sus efectos en tres momentos distintos: primero, en el acceso a la justicia; segundo, una vez en ella, en que sea posible la defensa y la obtención de la solución en un plazo razonable; tercero, una vez dictada sentencia, en la plena efectividad de sus pronunciamientos. Acceso a la jurisdicción, proceso debido y eficacia de la sentencia. 
Comencemos, entonces, a analizar si la conciliación contenciosa administrativa cumple actualmente con la garantía de la TJE y que los contenidos expuestos anteriormente se llevan por analogía a la conciliación contenciosa administrativa:

1. El derecho de acceso a la jurisdicción: el derecho de acceso a la jurisdicción lleva implícito el principio del juez natural, en este sentido, la sentencia C-755/13 sostiene que "[1]a Constitución prevé expresamente que "[n]adie podrá ser juzgado sino [...] ante juez o tribunal competente".

La sentencia T-916/14 incorpora lo que conlleva el juez natural, el cual supone

i) que el órgano judicial sea previamente creado por la ley; ii) que la competencia le haya sido atribuida previamente al hecho sometido a su decisión; iii) que no se trate de un juez por fuera de alguna estructura jurisdiccional (ex post) o establecido únicamente para el conocimiento de algún asunto (ad hoc); y iv) que no se someta un asunto a una jurisdicción especial cuando corresponde a la ordinaria o se desconozca la competencia que por fuero ha sido asignada a determinada autoridad judicial.

Por analogía, entonces, tenemos (Torres Osorio, 2013):

1.1. Que el órgano judicial haya sido creado previamente por ley $\leftrightarrow^{2}$ Que el órgano que va a desarrollar la conciliación contenciosa administrativa haya sido creado previamente por ley.

Los procuradores delegados en asuntos contenciosos administrativos son los designados por la ley para ser los conciliadores, esto está planteado desde el Decreto-ley 262 de 2000, en su artículo 30, así: "Funciones de intervención judicial en procesos contencioso-administrativos. Los procuradores delegados ejercen las siguientes funciones de intervención judicial en procesos contenciosos administrativos: [...] 5. Realizar las audiencias de conciliación prejudicial en asuntos de conocimiento en única instancia del Consejo de Estado" y el artículo 37 del Decreto-ley 262 de 2000, en su inciso

$2 \leftrightarrow$ o por analogía. segundo, establece: "Además de las funciones disciplinarias, de control de gestión y preventivas, los procuradores judiciales en lo contencioso administrativo tendrán funciones de conciliación en los términos señalados por las leyes que regulan esta materia".

Por su parte, el artículo 23 de la Ley 640 de 2001 indica que la conciliación contenciosa administrativa solo podrá ser adelantada ante los agentes del ministerio público asignados a esa jurisdicción; es decir, ante los procuradores delegados en asuntos contenciosos administrativos.

1.2. Que la ley lo haya investido de jurisdicción y competencia con anterioridad al hecho motivador de la actuación judicial $\leftrightarrow$ Que las leyes de conciliación lo hayan investido de competencia con anterioridad al hecho motivador de la actuación del conciliador.

"Se entiende por competencia objetiva el conjunto de normas procesales que distribuyen jerárquicamente, entre los diversos órganos judiciales de un mismo orden jurisdiccional, el conocimiento de la fase declarativa de los objetos procesales" (Gimeno Sendra, 2007, p. 75).

El artículo 23 de la Ley 640 de 2001 determinó que la conciliación contenciosa administrativa tiene competencia especial, pues las conciliaciones extrajudiciales en materia de lo contencioso administrativo solo podrán ser adelantadas ante los agentes del Ministerio Público asignados a esta jurisdicción.

Respecto a los factores de competencia, esta contiene tres aspectos, a saber:

a. Competencia por razón de la cuantía, definida por Gómez de Liaño González y Pérez Cruz Martín (2002) como

[e]l valor económico que se otorga a lo que es objeto del proceso, que sirve para determinar la clase de procedimiento a utilizar $y$, en consecuencia, el órgano jurisdiccional al que corresponde conocer, cuando no haya quedado ya fijado por razón de la materia. (p. 257)

Este factor no opera en la conciliación contenciosa administrativa, pues el agente del 
Ministerio Público (procurador delegado en asuntos contenciosos administrativos) no tiene cuantías fijadas para conocer de las conciliaciones contenciosas administrativas.

b. Competencia por razón de la materia que

[a]tiende a la naturaleza de los derechos deducidos o al tipo de tutela que se solicita, e incluso a la calidad de las personas enjuiciadas. Se determinan por ley, de forma casuística y, por razones de oportunidad, las que han de ser conocidas por uno u otro tribunal. (Gómez de Liaño González y Pérez Cruz Martín, 2002, p. 256)

En este sentido, el artículo 37 de la Ley 640 de 2001 manifiesta que

[...] [a]ntes de incoar cualquiera de las acciones previstas en los artículos 86 y 87 del Código Contencioso Administrativo, las partes, individual o conjuntamente, deberán formular solicitud de conciliación extrajudicial, si el asunto de que se trate es conciliable.

Como requisito de procedibilidad, entonces, se tiene que se debe intentar la conciliación en los medios de control establecidos en el CPACA así: artículo 138, nulildad y restablecimiento del derecho; artículo 140, acción de reparación directa y en el artículo 141 de controversias contractuales.

Otra conciliación que no es requisito de procedibilidad, pero que sí está adjudicada a los procuradores delegados, es la conciliación para la indemnización de perjuicios causados a víctimas de la violación a los derechos humanos, en virtud de decisiones de organismos internacionales de defensa de los derechos humanos, celebrada por el agente del Ministerio Público adscrito al tribunal contencioso administrativo (Ley 288 de 1996).

c. Las reglas sobre fuero por competencia territorial son las que nos permiten determinar qué juez de entre todos aquellos que existen dentro de un mismo grado a lo largo del territorio nacional es competente para entender de una determinada causa. En este sentido, en caso de que el agente del Ministerio Público no resulte competente en razón del factor territorial para conocer de la conciliación extrajudicial, lo remitirá al agente del Ministerio Público que tenga atribuciones para el efecto.

1.3. Que no sean especiales ni excepcionales sus regímenes orgánico y procesal, pero sí puede tratarse de jueces ordinarios con especiales competencias por razón de la materia o del territorio $\rightarrow$ Que no sean especiales ni excepcionales sus regímenes orgánico y procedimental, pero sí puede tratarse de conciliador y procedimientos especiales por razón de la materia u objeto de la conciliación.

Cuando se trate de conciliaciones en derecho administrativo, existen normas precisas ${ }^{3}$, cualidades y procedimientos especiales para los conciliadores o para las entidades que prestan este servicio de la misma forma que ya se

3 Ley 446 del 7 de julio de 1998. Capítulo 2. "Normas aplicables a la conciliación contenciosa administrativa”. Sección 2a, "De la Conciliación prejudicial en materia contenciosa administrativa":

- Antes de iniciar las acciones de los artículos 138, 140 y 141 del Código de Procedimiento Administrativo y de lo Contencioso Administrativo (Ley 1437 de 2011), podrán formular solicitud de conciliación prejudicial ante los agentes del Ministerio Público asignado al juez; esta conciliación debe llevar pruebas que fundamenten la petición.

- La conciliación administrativa prejudicial solo se puede intentar cuando no procediere la actuación administrativa y estuviere agotada.

- Ley 640 del 2001. Capítulo V. "De la conciliación contenciosa administrativa”:

Solo procede por los funcionarios debidamente autorizados para tal fin.

El auto que imparta aprobación de una audiencia de conciliación contenciosa, expedido por el juez o corporación competente, no será consultable.

En este tipo de conciliaciones (contenciosas administrativas) se pueden aportar pruebas y solicitar pruebas por el conciliador para establecer presupuestos de hecho y derecho para conformar el acuerdo conciliatorio. Se pueden aportar pruebas dentro de los veinte días siguientes a la solicitud (conciliación extrajudicial).

- Decreto 1716 del 14 de mayo de 2009, por medio del cual las normas del Decreto se aplicarán a la conciliación extrajudicial en asuntos contenciosos administrativos. 
ha establecido para la conciliación en derecho privado.

2. El derecho a obtener de los tribunales un procedimiento fundado en el derecho objetivo, que será de fondo cuando concurran todos los presupuestos procesales y que observará los requisitos de la motivación y de la congruencia $\leftrightarrow$ El derecho a un procedimiento de conciliación fundado en derecho objetivo y que observará la voluntad de los intervinientes y la congruencia legal.

La conciliación contenciosa administrativa es una de las más especiales que existe en Colombia respecto a los Mecanismos Alternativos de Solución de Controversias (MASC) porque tiene unos requisitos o etapas que son diferentes a las otras conciliaciones (civil, familiar, laboral). El procedimiento de conciliación debe dar las acciones, los pasos a seguir para llegar a lo que se pretende, sin olvidar que no tiene un fin específico, sino que es un medio a través del cual los intervinientes, por su libre albedrío, llegan o no a un acuerdo con la ayuda facilitadora del conciliador. Esto diferencia el procedimiento de conciliación del proceso judicial, pues en el último el fin es llegar a la sentencia. La Corte Constitucional, en la sentencia C-1195 de 2001, indicó que la justicia normal no siempre es efectiva ni idónea, por eso se requieren de procedimientos menos formales, como la conciliación, a través de los cuales, autocompositivamente, se llega a soluciones.

El término conciliación tiene dos sentidos distintos, según el contexto en que es utilizado: uno procedimental y otro sustancial. En relación con su acepción procedimental, la conciliación es "un mecanismo de resolución de conflictos a través del cual dos o más personas gestionan por sí mismas la solución de sus diferencias, con la ayuda de un tercero neutral y calificado, denominado conciliador" (Ley 446 de 1998, artículo 64). Según esta acepción, la conciliación es apenas una serie de pasos preestablecidos que tiene por objeto - eventual, no necesario- la celebración de un acuerdo entre dos o más personas. No obstante, el término conciliación también se refiere al acuerdo al que se llega mediante la celebración del procedimiento conciliatorio (ver Figura 1). En este segundo sentido sustancial, la conciliación se materializa en un acta que consigna el acuerdo al que llegan las partes, certificado por el conciliador.

Toda etapa de la conciliación contenciosa administrativa es realmente importante, comenzando por la realizada por el comité conciliador. El artículo 16 del Decreto 1716 de 2009 indica que

[e]l Comité de Conciliación es una instancia administrativa que actúa como sede de estudio, análisis y formulación de políticas sobre prevención del daño antijurídico y defensa de los intereses de la entidad.

Igualmente decidirá, en cada caso específico, sobre la procedencia de la conciliación o cualquier otro medio alternativo de solución de conflictos, con sujeción estricta a las normas jurídicas sustantivas, procedimentales y de control vigentes, evitando lesionar el patrimonio público. La decisión de conciliar tomada en los términos anteriores, por sí sola, no dará lugar a investigaciones disciplinarias, ni fiscales, ni al ejercicio de acciones de repetición contra los miembros del Comité.

Parágrafo único. La decisión del Comité de Conciliación acerca de la viabilidad de conciliar no constituye ordenación de gasto.

Las facultades del comité conciliador no pueden restringirse únicamente a la conciliación sino que corresponde también a todos los mecanismos de solución de conflictos y de terminación anticipada del proceso, cualquiera sea su modalidad. Esto incluye, entre otros, la transacción, la aprobación de la oferta de revocatoria directa de los actos administrativos que se hayan demandado ante la jurisdicción, la mediación de conflictos entre entidades públicas del orden nacional o el pacto de cumplimiento en acciones populares.

Como se desprende del artículo 16 del Decreto 1716 de 2009, la función principal del mal llamado comité de conciliación no es decidir si la entidad pública concilia o no, sin embargo, 
Figura 1. Diagrama de flujo: procedimiento de conciliación contenciosa administrativa

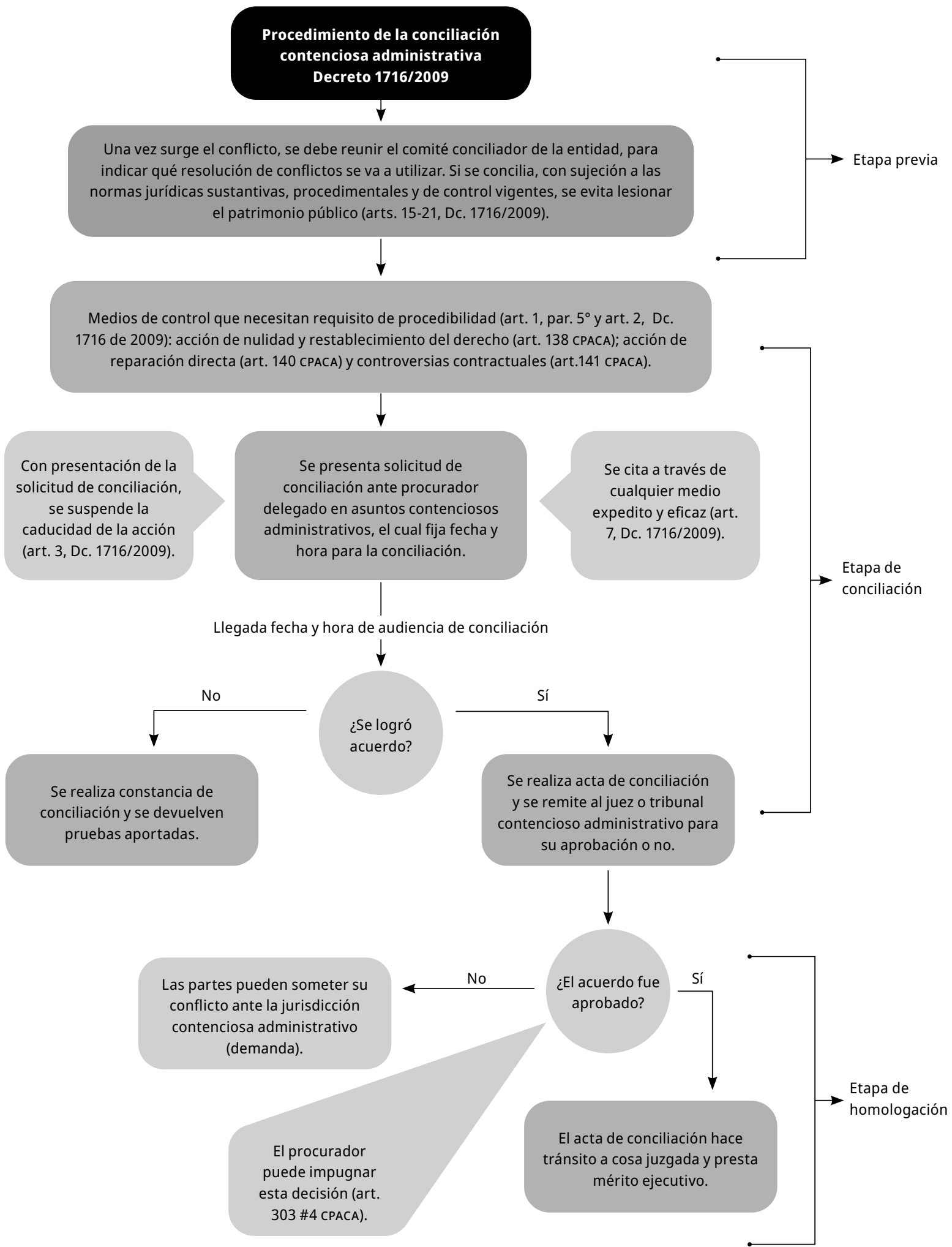

Fuente: elaboración propia. 
sí tienen que decidirlo cuando se enfrentan a demandas sobre los medios de control, que son requisito de procedibilidad.

Sin el acta que emita el comité de conciliación, la entidad no puede asistir a la conciliación contenciosa administrativa, ya sea que contenga un sentido positivo o negativo de llegar a un acuerdo o no. Sin embargo, hacemos la claridad de que este artículo no pretende estudiar las fallas o fortalezas que tenga este comité de conciliación respecto a la conciliación, pues se tendría que hacer un estudio sectorizado y completo para verificar si las conciliaciones contenciosas administrativas, en cuanto a su eficacia, fallan por las decisiones de este o por el temor de los funcionarios que lo componen a que posteriormente se les procese en acciones de repetición.

Una vez se obtiene el acta del comité conciliador, puede comparecer la entidad pública a la conciliación contenciosa administrativa, como convocante o como convocado, citada por el procurador contencioso administrativo.

A diferencia de la conciliación en el derecho privado, la conciliación contenciosa administrativa requiere, desde el primer momento, la presencia del abogado del convocante, quien debe presentar la solicitud de conciliación (con los requisitos contenidos en el artículo 6 del Decreto 2511 de 1998) ante el procurador delegado en asuntos contenciosos administrativos y debe comparecer a todas las sesiones de conciliación (parágrafo 3 , artículo 1, Ley 640 de 2001).

El procurador, por tanto, es el conciliador. Este no se designa ni se escoge; si existen varios procuradores delegados, el conocimiento de una conciliación les toca por reparto. El procurador desarrolla el proceso de conciliación en el cual las partes pueden llegar a un acuerdo total o parcial, levanta el acta de conciliación y la debe remitir a la jurisdicción contenciosa administrativa para que sea homologada.

Como se observa, el procedimiento está muy regulado y es complejo, pues el acuerdo, como se verá más adelante, en la mayoría de los casos, no es homologado por el juez o el tribunal contencioso administrativo.

3. El derecho a los recursos que las leyes establezcan contra las resoluciones judiciales $\leftrightarrow E l$ derecho a los recursos que las leyes establezcan sobre las resoluciones judiciales que tengan que ver con la conciliación.

El artículo 89 de la CP indica:

Además de los consagrados en los artículos anteriores, la ley establecerá los demás recursos, las acciones, y los procedimientos necesarios para que puedan propugnar por la integridad del orden jurídico, y por la protección de sus derechos individuales, de grupo o colectivos, frente a la acción u omisión de las autoridades públicas.

Pese a lo indicado en la norma constitucional antes citada, el artículo 243, numeral 4, de la Ley 1437 de 2011 se manifiesta así:

Apelación. Son apelables las sentencias de primera instancia de los Tribunales y de los Jueces. También serán apelables los siguientes autos proferidos en la misma instancia por los jueces administrativos [...].

4. El que apruebe conciliaciones extrajudiciales o judiciales, recurso que solo podrá ser interpuesto por el Ministerio Público. [...]".

El numeral 4 del artículo 243 del CPACA constituye una vulneración del derecho a los recursos que las leyes establezcan sobre las resoluciones judiciales que tengan que ver con la conciliación, toda vez que solo el procurador puede interponer el recurso, pero no las partes (convocante y el convocado) de la conciliación contenciosa administrativa, a quienes les está vedado apelar el auto que apruebe la conciliación.

Lo anterior no ocurría antes de la expedición del artículo 243, numeral 4, de la Ley 1437 de 2011, pues el anterior régimen contencioso administrativo contenía la apelación del auto que aprobaba o improbaba el acuerdo, tal como se puede corroborar en las siguientes sentencias: 
- Radicación número: 25000-23-26-000-201101124-01(43468), de fecha 5 de junio de 2012, (consejera ponente: Stella Conto Díaz del Castillo).

- Radicación número: 25000-23-26-000-201100582-01 (42881), de fecha 23 de mayo de 2012 (consejera ponente: Olga Melida Valle de La Hoz).

- Radicación número: 25000-23-25-000-201000728-01, de fecha 6 de mayo de 2011, (consejera ponente: Gerardo Arenas Monsalve).

En cuanto al principio de la doble instancia (artículo 31 de la CP), la Corte Constitucional en sentencia T-633/2009 ha precisado que no tiene "un carácter absoluto en las sentencias". Ciertamente, la doble instancia tiene un vínculo estrecho con el debido proceso y el derecho de defensa, por ello, se hace necesaria la revisión del mismo por las siguientes razones:

- El auto que aprueba y homologa parcial o totalmente una conciliación o que no la aprueba, por tanto, no la homologa, al no poder ser recurrido por el apoderado de la entidad pública, este puede perder el momento procesal, toda vez que puede existir un cambio de abogado o de mandato de alcalde o de directivo representante legal de la entidad pública, y entre uno y otro el criterio de los que lo suceden puede variar. En igual sentido puede ocurrir con los argumentos con los que se logró el acuerdo conciliatorio.

- Si solo se deja esta facultad al procurador delegado ante la jurisdicción contenciosa administrativa, puede pasar que esta no argumente en debida forma la apelación del auto y se pierde el momento procesal.

El numeral 4 del artículo 243 de la Ley 1437 de 2011 es taxativo, lo que hace que se aplique, pero que, por su rigurosidad, se deje de emplear en otros casos en los que se requiere. Asimismo, vulnera ostensiblemente las siguientes garantías procesales estatuidas en la CP del debido proceso: "Artículo 29. El debido proceso se aplicará a toda clase de actuaciones judiciales y administrativas [...]".
La norma antes citada es de interpretación restrictiva, es decir, que limita el alcance de la misma apartando de ella determinados supuestos que se encontrarían incluidos de acuerdo con la redacción de su texto, pero que se entiende que no fue voluntad del legislador comprenderlos dentro de este.

Con la interpretación restrictiva se reduce el alcance del texto de la norma. La interpretación restrictiva se aplica preferentemente a las normas prohibitivas y a las especiales, en las cuales la consecuencia jurídica se aplica estrictamente a los casos descritos en el supuesto de hecho. Por lo tanto, el carácter restrictivo consagrado en la norma citada contraría la TJE y contiene, por tanto, una vulneración a los fundamentos constitucionales.

4. El derecho a la ejecución de las resoluciones judiciales $\leftrightarrow$ El derecho a la ejecución del acuerdo logrado en conciliación.

Otro aspecto importante y problemático de la efectividad de la tutela jurisdiccional tiene que ver con la existencia de instrumentos adecuados de ejecución coactiva de las decisiones judiciales. Así las cosas y tal como lo indica Taruffo (1996):

En efecto, una tutela que se detenga en el reconocimiento formal del derecho no es efectiva si la satisfacción real de ese derecho acaba por depender solamente de la buena voluntad del sujeto obligado. Por el contrario, parece que solo se podrá hablar de tutela efectiva cuando el ordenamiento judicial disponga de instrumentos ejecutivos eficaces para obtener la ejecución de cualquier resolución jurisdiccional. (p. 143)

Para llegar a obtener esta garantía, el juez o tribunal contencioso administrativo debe haber homologado el acuerdo de conciliación en la conciliación contenciosa administrativa, cosa que no es fácil de obtener y lo cual se ve en las cifras de actas conciliadas de las Gráficas 1 y 2 y en la Tabla 1. 
Gráfica 1. Conciliaciones contenciosas administrativas con acuerdo total entre 2016 y primer semestre del 2020

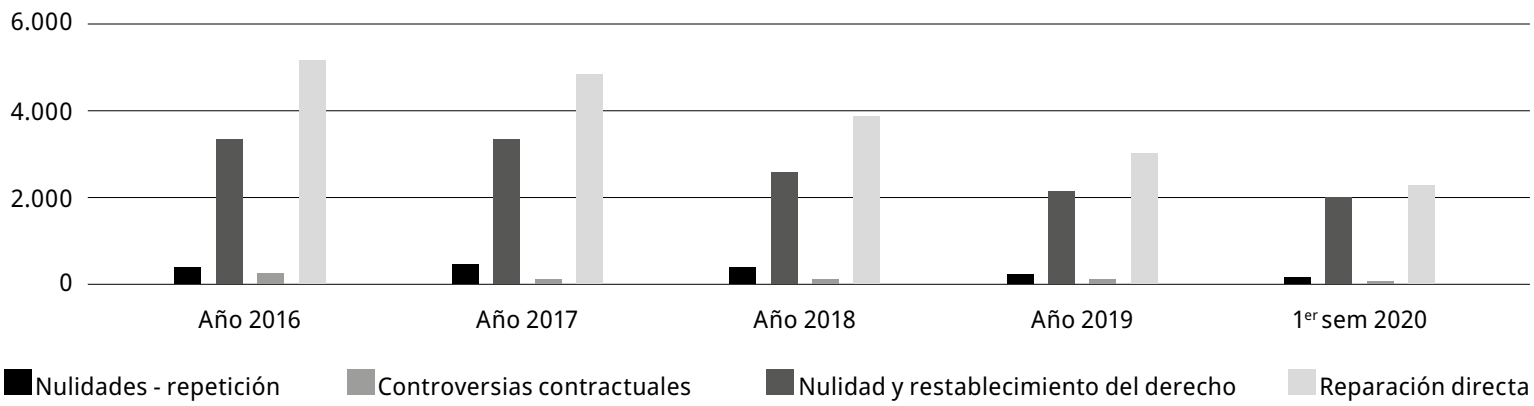

Fuente: elaboración propia.

Gráfica 2. Acuerdos conciliatorios aprobados por la jurisdicción contenciosa administrativa entre 2016 y primer semestre del 2020

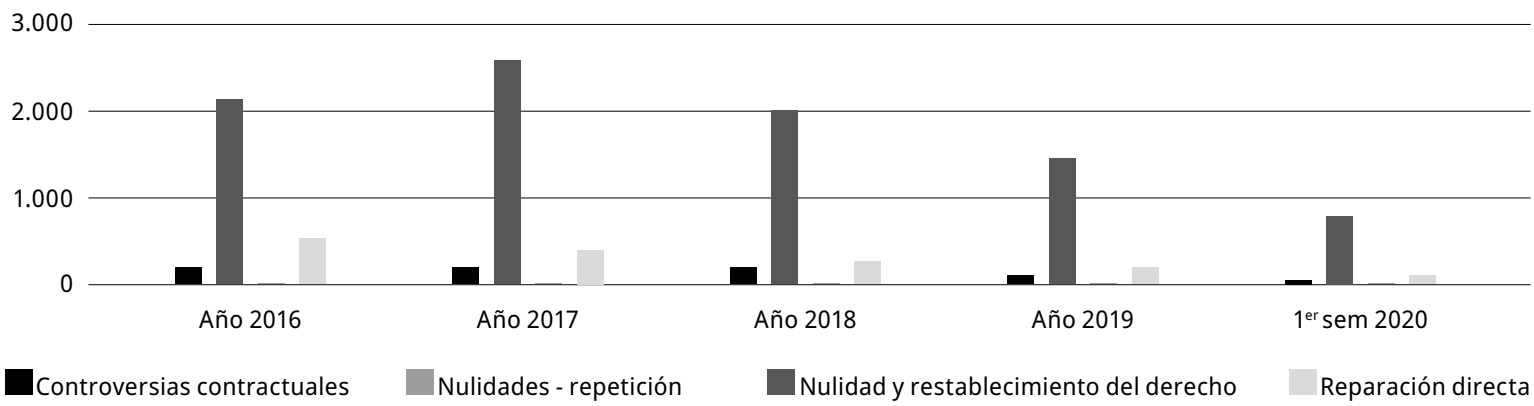

Fuente: elaboración propia.

Tabla 1. Medio de control, acuerdos totales logrados en conciliaciones contenciosas administrativas y homologaciones por la jurisdicción contenciosa administrativa en el periodo 2016 al primer semestre de 2020
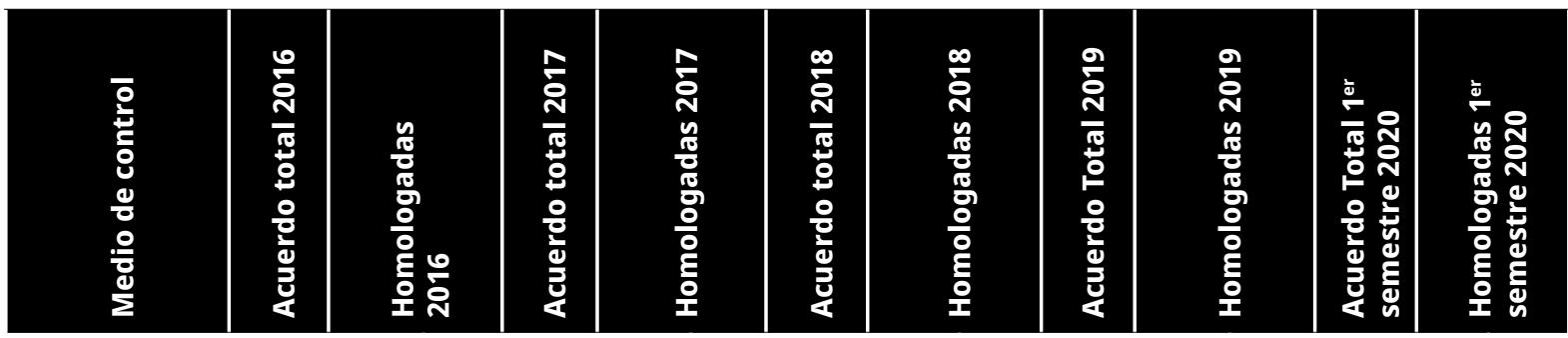

Controversias

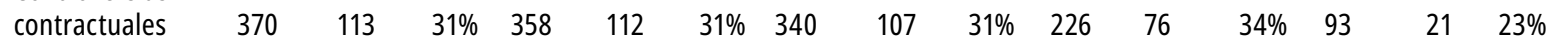

Nulidad y

restablecimiento

del derecho

$\begin{array}{lllllllllllllll}3.555 & 2.205 & 62 \% & 3.595 & 2.565 & 71 \% & 2.686 & 1.996 & 74 \% & 2.102 & 1.388 & 66 \% & 2.020 & 781 & 39 \%\end{array}$

Nulidades -

\begin{tabular}{llllllllllllllll} 
repetición & 84 & 15 & $18 \%$ & 87 & 12 & $14 \%$ & 78 & 4 & $5 \%$ & 65 & 2 & $3 \%$ & 25 & 2 & $8 \%$ \\
\hline
\end{tabular}

Reparación

directa

$\begin{array}{lllllllll}5.159 & 411 & 8 \% & 4.821 & 312 & 6 \% & 3.868 & 192 & 5 \%\end{array}$

Fuente: elaboración propia. Datos obtenidos de la respuesta a un derecho de petición. 
De los datos remitidos por la procuraduría delegada para la conciliación contenciosa administrativa a la respuesta del derecho de petición realizado por la autora, se tiene que los acuerdos homologados en controversias contractuales, nulidades por repetición y reparación directa en los últimos cuatro años y el primer semestre del año 2020 no superan el $30 \%$ a ser homologados por el juez o el tribunal contencioso administrativo, excepto en el medio de control de nulidad y de restablecimiento del derecho, para los cuales se han homologado por encima del $60 \%$ de los acuerdos obtenidos en los mismos años.

No se pueden aseverar en esta investigación las razones por las cuales la jurisdicción contenciosa administrativa no aprueba las conciliaciones, por lo que estos datos se deben investigar de forma sectorizada por región para así poder comprobar dónde se está fallando en la primera etapa (comité de conciliación de las entidades públicas) o en la etapa de conciliación ante el procurador delegado.

Por lo anterior, se puede indicar a grandes rasgos que no se logra efectividad en la conciliación contenciosa administrativa. Otra cosa que se debe verificar es el tiempo que duran estas etapas, para poder definir si la conciliación como requisito de procedibilidad antes de ser una ayuda se está convirtiendo en una talanquera para lograr una verdadera tutela judicial efectiva. Esta última estaría siendo afectada o vulnerada por un trámite conciliatorio que tiene fallas en su procedimiento.

5. El derecho a la inmodificabilidad de las resoluciones judiciales firmes fuera de los cauces legalmente establecidos al efecto $\boldsymbol{H}$ El derecho a la inmodificabilidad en los acuerdos logrados en conciliación.

Los efectos de cosa juzgada de la conciliación contenciosa administrativa solo quedan en firme una vez el acuerdo total o parcial haya logrado homologación por la jurisdicción, como se indicó anteriormente.

De la Oliva Santos (1991, p. 23) manifiesta que la cosa juzgada material subviene (como la cosa juzgada formal, pero en mayor medida y más claramente) a la seguridad y a la paz jurídicas. A esas necesidades sirve una vinculación que impida: 1) que una discusión jurídica se prolongue indefinidamente y se vuelva a entablar acerca de un asunto ya definido firmemente por la jurisdicción, 2) que se produzcan resoluciones y sentencias contradictorias o que se reiteren, injusta e irracionalmente, sentencias con el mismo contenido sobre el mismo asunto.

Al no poseer el acuerdo logrado en la conciliación ante el procurador delegado en asuntos contenciosos administrativos el efecto de cosa juzgada, no se puede impedir que sea demandado en un proceso posterior con idéntico objeto, no se puede proponer la excepción de cosa juzgada.

Una vez el acta de conciliación contenciosa administrativa haya sido homologada, cumple con todos los requisitos de la cosa juzgada, lo que da certeza a las partes de la inmodificabilidad del acuerdo. Esto les imprime el efecto de la cosa juzgada, logrando, por tanto, tener esta garantía de la TJE.

6. El derecho a no sufrir indefensión en el proceso $\leftrightarrow$ El derecho a no sufrir indefensión en la conciliación.

El derecho a no sufrir indefensión tiene unas características constitucionales, a saber:

6.1 Derecho a no padecer indefensión y obligación judicial de impedir indefensión. La sentencia C-1195/01 indica:

La obligatoriedad de la audiencia de conciliación prejudicial y los efectos que tiene el acta de conciliación en caso de que las partes lleguen a un acuerdo no elimina la posibilidad de que estas tengan acceso a un recurso judicial efectivo. Ante posibles fallas ocurridas dentro del procedimiento conciliatorio, - como cuando se desconoce el debido proceso, se afectan derechos de terceros que no participaron en la conciliación, se tramitan a través de la conciliación asuntos excluidos de ella, se desconocen derechos de personas que se encuentran en condiciones de indefensión o se concilian derechos no 
renunciables - que lleguen a constituir una vulneración o amenaza de derechos fundamentales, procedería la acción de tutela. En materia contencioso administrativo, el legislador previó la aprobación judicial como mecanismo de control judicial de la conciliación en estas materias.

En la conciliación, son titulares para no sufrir indefensión los intervinientes y los terceros que deban ser llamados a ella, por beneficiarles o perjudicarles el acuerdo. Se debe, igualmente, respetar el derecho a la libre discusión del conflicto de una manera respetuosa. Se pueden aportar documentos probatorios, pero estos deben ser valorados y aceptados por los intervinientes, siendo ellos quienes deciden sobre su confidencialidad o aportación en un posterior proceso judicial.

El derecho a que los intervinientes no experimenten indefensión debe estar garantizado por el conciliador, quien vela en todo el procedimiento de conciliación por los intervinientes (y terceros) y por la seguridad jurídica de sus acuerdos.

6.2. Requisitos para la apreciación de la indefensión.

En relación con la indefensión, por su parte, la Corte ha señalado que

[...] esta alude a aquellas situaciones en las que la persona no cuenta con la posibilidad material de hacer frente a las amenazas o a las transgresiones de otra, en algunas ocasiones por la ausencia de medios ordinarios de defensa y en otras porque estos resultan exiguos para resistir el agravio particular del que se trata. Así, ha precisado que "el estado de indefensión es un concepto de naturaleza fáctica que se configura cuando una persona se encuentra en un estado de debilidad manifiesta frente a otra, de modo que, por el conjunto de circunstancias que rodean el caso, no le es posible defenderse ante la agresión de sus derechos", bien porque se "carece de medios jurídicos de defensa" o porque "a pesar de existir dichos medios, los mismos resultan insuficientes para resistir o repeler la vulneración o amenaza de sus derechos fundamentales". (Sentencia T-145/16)

En la conciliación, se garantiza que los intervinientes no sufran indefensión a través de:

- La aplicación de los principios que la rigen (es de aclarar que estos principios no están contemplados en las leyes de conciliación; estos son: voluntariedad, igualdad de las partes, confidencialidad, carácter personalísimo, imparcialidad, flexibilidad, oralidad, neutralidad y buena fe).

- La garantía de prestación del servicio gratuito.

- El régimen sancionador establecido para las posibles infracciones que cometa el conciliador-procurador.

- El procedimiento de recusación y abstención del conciliador-procurador.

- La posibilidad de nulidad del acuerdo logrado en conciliación o del procedimiento de conciliación.

Sin embargo, se puede indicar que se sufre indefensión en la conciliación contenciosa administrativa al no dejar interponer recurso contenido en el numeral 4 del artículo 243 de la Ley 1437 de 2011 a todos los intervinientes de la conciliación, únicamente al poderlo hacer el ministerio público y en el tiempo en que se tarda conseguir la homologación del acuerdo, sin saber si logrará la homologación o no (Tabla 2). 
Tabla 2. Resumen de la TJE en la conciliación contenciosa administrativa

\begin{tabular}{|c|c|c|c|c|c|}
\hline $\begin{array}{l}\text { Derecho de } \\
\text { acceso a la } \\
\text { jurisdicción }\end{array}$ & $\begin{array}{l}\text { Derecho a un } \\
\text { procedimiento } \\
\text { de conciliación } \\
\text { fundado } \\
\text { en derecho } \\
\text { objetivo, y } \\
\text { que observa la } \\
\text { voluntad de los } \\
\text { intervinientes } \\
\text { y congruencia } \\
\text { legal }\end{array}$ & $\begin{array}{l}\text { Derecho a los } \\
\text { recursos }\end{array}$ & $\begin{array}{l}\text { Derecho a } \\
\text { la ejecución } \\
\text { del acuerdo } \\
\text { logrado en } \\
\text { conciliación }\end{array}$ & $\begin{array}{l}\text { Derecho a la } \\
\text { inmodificabilidad } \\
\text { de los acuerdos } \\
\text { logrados en } \\
\text { conciliación }\end{array}$ & $\begin{array}{l}\text { Derecho a } \\
\text { no sufrir } \\
\text { indefensión } \\
\text { en la } \\
\text { conciliación }\end{array}$ \\
\hline $\begin{array}{l}\text { Sí, toda vez que } \\
\text { se le otorgue } \\
\text { al procurador } \\
\text { delegado en asuntos } \\
\text { contenciosos } \\
\text { administrativos } \\
\text { la función de ser } \\
\text { conciliador en dicha } \\
\text { especialidad. }\end{array}$ & $\begin{array}{l}\text { Sí, pese a que el } \\
\text { procedimiento } \\
\text { es complejo, sin } \\
\text { embargo, hay que } \\
\text { detectar, a través } \\
\text { de investigaciones } \\
\text { por regiones, dónde } \\
\text { está fallando el } \\
\text { procedimiento } \\
\text { de la conciliación } \\
\text { contenciosa } \\
\text { administrativa, } \\
\text { pues son pocos } \\
\text { los acuerdos } \\
\text { homologados en la } \\
\text { jurisdicción. }\end{array}$ & $\begin{array}{l}\text { Se vulnera, } \\
\text { toda vez que los } \\
\text { intervinientes en } \\
\text { la conciliación } \\
\text { contenciosa } \\
\text { administrativa } \\
\text { no pueden } \\
\text { interponer } \\
\text { recurso de } \\
\text { apelación al auto } \\
\text { que aprueba } \\
\text { la conciliación } \\
\text { (artículo 243, N. } \\
4 \text { del CPACA). }\end{array}$ & $\begin{array}{l}\text { Sí se cumple, } \\
\text { pero son pocos } \\
\text { los acuerdos } \\
\text { homologados por } \\
\text { la jurisdicción } \\
\text { contenciosa } \\
\text { administrativa. }\end{array}$ & $\begin{array}{l}\text { Una vez el acta } \\
\text { de conciliación } \\
\text { contenciosa } \\
\text { administrativa haya } \\
\text { sido homologada, } \\
\text { cumple con todos los } \\
\text { requisitos de la cosa } \\
\text { juzgada, lo que da } \\
\text { certeza a las partes de } \\
\text { la inmodificabilidad } \\
\text { del acuerdo y les } \\
\text { imprime el efecto } \\
\text { de la cosa juzgada, } \\
\text { logrando, por tanto, } \\
\text { tener esta garantía de } \\
\text { la tjE. }\end{array}$ & $\begin{array}{l}\text { Se cumple en } \\
\text { cuanto a la } \\
\text { gratuidad de } \\
\text { la conciliación } \\
\text { y a la eficacia } \\
\text { que otorga la } \\
\text { homologación, } \\
\text { porque, si se } \\
\text { homologa, } \\
\text { significa que el } \\
\text { juez revisó todo } \\
\text { lo pertinente } \\
\text { a nulidad, a } \\
\text { capacidad y a } \\
\text { otros temas } \\
\text { importantes } \\
\text { para que el } \\
\text { acuerdo quede } \\
\text { perfeccionado. }\end{array}$ \\
\hline
\end{tabular}

\section{Conclusiones}

Al comparar analógicamente el contenido de la tutela judicial efectiva en la conciliación contenciosa administrativa encontramos que:

- Se cumple el derecho de acceso a la jurisdicción, toda vez que se le otorga la función de desarrollar la conciliación contenciosa administrativa al procurador delegado en asuntos contenciosos administrativos, al cual la ley le otorgó jurisdicción y competencia.

- Cuando el legislador determina la conciliación contenciosa administrativa como requisito de procedibilidad antes de demandar en los medios de control contempladas en los artículos 138, Nulidad y restablecimiento del derecho; 140 , Acción de reparación directa y 141, De controversias contractuales, el legislador garantiza que esta se preste en todo el territorio nacional a través de los agentes del Ministerio Público de forma gratuita.

- La conciliación contenciosa administrativa tiene un procedimiento complejo, diferente al de la conciliación extrajudicial en el derecho privado, el cual tiene tres etapas que se deben de cumplir de manera rigurosa. La primera es la reunión del comité de conciliación, que se realiza al interior de la entidad pública, las decisiones a las que lleguen, de permitir conciliar o no a la entidad, deben estar contenidas en una acta, la cual se debe anexar a la conciliación. La segunda etapa, que comienza cuando se recibe la solicitud de conciliación presentada a través de apoderado judicial, una vez recibida por el procurador delegado en asuntos contenciosos administrativos, este revisa que se cumplan los requisitos de la solicitud y fija fecha y hora para realizar sesiones de conciliación, 
a las cuales invita a asistir a la defensa jurídica del Estado; las partes deben asistir siempre con sus apoderados judiciales; en esta etapa se logran acuerdos totales o parciales. La tercera etapa es la homologación del acuerdo por parte de la jurisdicción contenciosa administrativa.

- La norma contenida en el numeral 4 del artículo 243 de la Ley 1437 de 2011 vulnera el derecho a los recursos que las leyes establezcan sobre las resoluciones judiciales.

- Los efectos de cosa juzgada de la conciliación contenciosa administrativa solo quedan en firme una vez el acuerdo total o parcial haya logrado homologación, pero la mayoría de los acuerdos logrados no llegan a ser homologados, lo que hace poco atractiva y eficiente la conciliación contenciosa administrativa.

- A quien corresponde garantizar la indefensión de las partes en el procedimiento conciliatorio en primera instancia es al procurador delegado en asuntos contenciosos administrativos, respetando, en debida forma, los principios de la conciliación y las normas y principios generales del derecho contencioso administrativo. En segunda instancia, es al juez o tribunal contencioso administrativo, en el momento de revisar el acuerdo logrado y otorgarle o no la homologación, el que concluye que, al no homologarlo, es porque han detectado un error o vulneración de alguna norma contenciosa administrativa en ella.

- La conciliación contenciosa administrativa no es eficiente, pues se pueden lograr acuerdos, pero, por razones que no han sido estudiadas, no se homologan los acuerdos en la jurisdicción.

Se recomienda que el legislador revise y modifique el artículo 243 numeral 4 del CPACA para garantizar el debido proceso y la doble instancia en el proceso de conciliación contenciosa administrativa.

Se requiere de más investigación en las regiones para hacer seguimiento a las conciliaciones y acuerdos logrados, verificando las razones que aducen los tribunales y juzgados contenciosos administrativos para no homologar acuerdos, lo que arrojará datos para hacer las debidas correcciones al procedimiento de la conciliación contenciosa administrativa.

\section{Referencias}

Constitución Política Española [Const]. Artículo 25, 27 de septiembre de 2011. 1978 (España). http://noticias.juridicas.com/base_datos/onstitucióntucion.t1.html\#a24

Constitución Política de Colombia [Const]. Artículos 29, 31, 89, 229. 1991 (Colombia). http://www.secretariasenado.gov.co/senado/basedoc/constitucion_politica_1991.html\#31

Decreto 1716. Por el cual se reglamenta el artículo 13 de la Ley 1285 de 2009, el artículo 75 de la Ley 446 de 1998 y del Capítulo V de la Ley 640 de 2001. Presidencia de la República de Colombia. http://www.suin-juriscol.gov. co/viewDocument.asp?ruta=Decretos $/ 1336533$

De la Oliva Santos, A. (1991). Sobre la cosa juzgada (civil, contencioso-administrativa y penal, con examen de la jurisprudencia del Tribunal Constitucional). Centro de Estudios Ramón Areces.

Garberí Llobregat, J. (2008). El derecho a la tutela judicial efectiva en la jurisprudencia del Tribunal Constitucional. Bosch.

Gimeno Sendra, J. V. (2007). Derecho procesal civil I. El proceso de declaración. Parte general (2a ed.). Colex.

González Pérez, J. (2001). El derecho a la tutela jurisdiccional ( $3^{\text {a }}$ ed.). Editorial Civitas.

Gómez de Liaño González, F. y Pérez Cruz Martín, A. (2002). Derecho procesal civil I (2a ed.). Editorial Forum.

Ley 446, artículo 64 (1998, 8 de julio). Congreso de la República de Colombia. Diario Oficial N. ${ }^{0} 43.335$. https:// www.oas.org/dil/esp/ley_446_de_1998_colombia.pdf

Ley 640 (2001, 5 de enero). Por la cual se modifican normas relativas a la conciliación y se dictan otras disposiciones. Congreso de la República de Colombia. Diario Oficial N.o 44.303. http://www.secretariasenado.gov. co/senado/basedoc/ley_0640_2001.html\#23

Ley 1437 de 2011 (18 de enero). Por la cual se expide el Código de Procedimiento Administrativo y de lo Contencioso Administrativo. Congreso de la República de Colombia. https://www.funcionpublica.gov.co/eva/ gestornormativo/norma.php?i=41249

Sentencia C-1195/2001. (2001, 15 de noviembre). Corte Constitucional. (Manuel José Cepeda Espinosa y Marco Gerardo Monroy Cabra, M.P.). 
Sentencia C-426/2002. (2002, 29 de mayo). Corte Constitucional. (Rodrigo Escobar Gil, M.P.).

Sentencia T-633/2009. (2009, 15 de septiembre). Corte Constitucional. (Mauricio González Cuervo, M.P.).

Sentencia C-248/2013. (2013, 24 de abril ). Corte Constitucional. (Mauricio González Cuervo M.P.).

Sentencia C-755/2013. (2013, 31 de octubre). Corte Constitucional. (María Victoria Calle Correa, M.P.).

Sentencia T-916/2014. (2014, 1 de diciembre). Corte Constitucional. (Martha Victoria Sáchica Méndez, M.P.).

Sentencia T-145/2016. (2016, 31 de marzo). Corte Constitucional. (Luis Guillermo Guerrero Pérez).

Sentencia C-159/2016. (2016, 6 de abril). Corte Constitucional. (Luis Ernesto Vargas Silva M.P.).

Sentencia T-550/2016. (2016, 11 de octubre ). Corte Constitucional. (Aquiles Arrieta Gómez, M.P.).

Sentencia T-608/2019. (2019, 12 de diciembre). Corte Constitucional. (Gloria Stella Ortiz Delgado, M.P.).
Radicación número: 25000-23-25-000-2010-00728-01. (2011, 6 de mayo). Consejo de Estado. (Gerardo Arenas Monsalve, C.P.).

Radicación número: 25000-23-26-000-2011-01124-01(43 468). (2011, 5 de junio). Consejo de Estado. (Stella Conto Díaz del Castillo, C.P.).

Radicación número: 25000-23-26-000-2011-00582-01 (428 81). (2012, 23 de mayo). Consejo de Estado. (Olga Melida Valle de La Hoz, C.P.).

Taruffo, M. (1996). La justicia civil: ¿opción residual o alternativa posible? En P. A. Ibáñez. (Coord.). Corrupción y Estado de derecho: el papel de la jurisdicción (pp. 135-150). Trotta.

Torres Osorio, E. (2013). La mediación a la luz de la tutela judicial efectiva. Colección Vítor. Ediciones Universidad de Salamanca. 